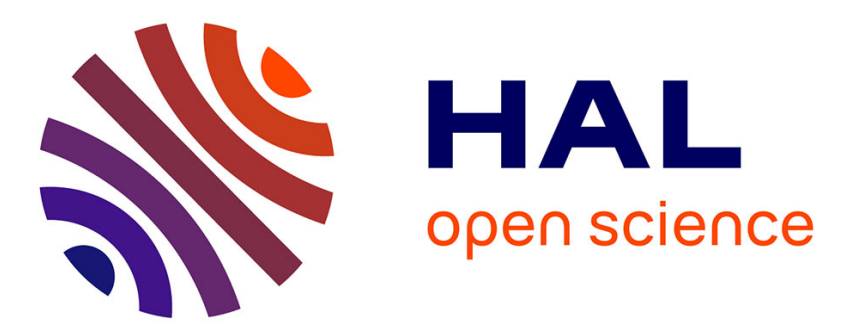

\title{
Semi-volatile organic compounds in the air and dust of 30 French schools: a pilot study
}

Gaëlle Raffy, Fabien Mercier, Olivier Blanchard, Mickaël Derbez, Claire Dassonville, Nathalie Bonvallot, Philippe Glorennec, Barbara Le Bot

\section{- To cite this version:}

Gaëlle Raffy, Fabien Mercier, Olivier Blanchard, Mickaël Derbez, Claire Dassonville, et al.. Semivolatile organic compounds in the air and dust of 30 French schools: a pilot study. Indoor Air, 2017, 27 (1), pp.114-127. 10.1111/ina.12288 . hal-01286254

HAL Id: hal-01286254

https://hal-univ-rennes1.archives-ouvertes.fr/hal-01286254

Submitted on 2 Jun 2016

HAL is a multi-disciplinary open access archive for the deposit and dissemination of scientific research documents, whether they are published or not. The documents may come from teaching and research institutions in France or abroad, or from public or private research centers.
L'archive ouverte pluridisciplinaire HAL, est destinée au dépôt et à la diffusion de documents scientifiques de niveau recherche, publiés ou non, émanant des établissements d'enseignement et de recherche français ou étrangers, des laboratoires publics ou privés. 


\title{
Semi-volatile organic compounds in the air and dust of 30 French
}

\section{schools: a pilot study}

RAFFY Gaëlle ${ }^{1,2,3 *} ;$ MERCIER Fabien ${ }^{1,2,3} ;$ BLANCHARD Olivier ${ }^{1,2} ;$ DERBEZ Mickaël ${ }^{4}$; DASSONVILLE Claire ${ }^{4}$; BONVALLOT Nathalie ${ }^{1,2}$; GLORENNEC Philippe $e^{1,2} ;$ LE BOT Barbara $^{1,2,3}$

${ }^{1}$ EHESP - School of public health Sorbonne Paris Cité, Rennes, France

${ }^{2}$ Irset-Inserm UMR 1085- Research institute for environmental and occupational health, Rennes, France

${ }^{3}$ LERES - Environment and health research laboratory, Rennes, France

${ }^{4}$ Université Paris Est, CSTB - Scientific and technical centre for building, OQAI - French indoor air quality observatory, Marne-la-Vallée, France

\begin{abstract}
The contamination of indoor environments with chemical compounds released by materials and furniture, such as semi-volatile organic compounds (SVOCs) is less documented in schools than in dwellings - yet children spend $16 \%$ of their time in schools, where they can also be exposed. This study is one of the first to describe the contamination of the air and dust of 90 classrooms from 30 nursery and primary schools by 55 SVOCs, including pesticides, phosphoric esters, musks, polycyclic aromatic hydrocarbons (PAHs), polychlorobiphenyls (PCBs), phthalates and polybromodiphenylethers (PBDEs). Air samples were collected using an active sampling method, and dust samples were collected via two sampling methods (wiping and vacuum cleaning). In air, the highest concentrations (median $>100 \mathrm{ng} / \mathrm{m}^{3}$ ) were measured for diisobutyl-phthalate (DiBP),
\end{abstract}


dibutyl-phthalate (DBP), diethyl-phthalate (DEP), bis(2-ethylhexyl)-phthalate (DEHP) and galaxolide. In dust, the highest concentrations (median > $30 \mu \mathrm{g} / \mathrm{g}$ ) were found for DEHP, diisononyl-phthalate (DiNP), DiBP and DBP. An attempt to compare two floor dust sampling methods using a single unit $\left(\mathrm{ng} / \mathrm{m}^{2}\right)$ was carried out. SVOC concentrations were higher in wiped dust, but frequencies of quantification were greater in vacuumed dust.

Keywords: SVOCs, children's exposure, indoor air, dust, school, sampling.

Practical implications: This pilot study shows that phthalate concentrations in schools are not negligible and should be considered in risk assessment via air inhalation or dust ingestion.

\section{Introduction}

People spend more than $80 \%$ of their time indoors (Hussein et al., 2012; Klepeis et al., 2001), where they are exposed to a wide range of chemical compounds such as semi-volatile organic compounds (SVOCs), emitted by building materials and consumer products. SVOCs include a group of chemical compounds defined by their volatility and vapor pressure: their boiling point is between $240^{\circ} \mathrm{C}$ and $400^{\circ} \mathrm{C}$, and their vapor pressure ranges from $10^{-14}$ to $10^{-4}$ atm (Weschler and Nazaroff, 2008; WHO, 1989).

Some SVOCs have been present in indoor environments since the 1950s (Weschler, 2009). Polybromodiphenylethers (PBDEs), for example, have been used as flame retardants in products such as foam cushioning, mattresses and electronic devices; polychlorobiphenyls (PCBs) originated from heat transfer fluids or joint sealants (Kohler et al., 2005), and although no longer manufactured, are still present in indoor environments; phthalates are used as plasticizers, especially for flexible polyvinyl chloride (PVC) (Weschler, 2009); polycyclic aromatic hydrocarbons (PAHs) develop during incomplete combustion processes such as heating with fossil fuels, cooking or outdoor motorized traffic (Fromme et al., 2004). Pesticides may be added 
to carpets, paints or furnishings or they can be brought into the home after being used outdoors (Rudel and Perovich, 2009). Synthetic musks, as a group of fragrance ingredients, have been widely used in a range of personal care products (Roosens et al., 2007).

SVOCs are suspected of having adverse health effects such as reprotoxic and neurotoxic effects (Fournier et al., 2014). Children are more vulnerable to the harmful effects of pollutants because major systems of their organism are still immature. Children's exposure to SVOCs during development (in utero, infants and children) can result in permanent alterations in tissue structure and function, notably because of endocrine disrupting mechanisms (Rudel and Perovich, 2009).

The physical and chemical properties of SVOCs lead to their emission into indoor air and then to their partition between air (gas and particulate phases) and surfaces (settled dust) (Weschler and Nazaroff, 2010). People are thus exposed through air inhalation, dust ingestion and dermal contact. Children are more exposed than adults because they have higher ventilation rates and higher levels of physical activity (Rivas et al., 2014). Their specific behavior (crawling on the floor, hand to mouth contact, object to mouth contact) may also contribute to a higher ingestion of settled dust (EPA, 2011; Oomen, 2008), even though current estimates of children's exposure to SVOC via dust are subject to a high level of uncertainty.

Numerous studies relating to household contamination by SVOCs (Ali et al., 2012; Blanchard et al., 2014; Kanazawa et al., 2010; Le Cann et al., 2011; Meeker and Stapleton, 2010; Mercier et al., 2011) have been published in recent years. Studies investigating SVOC contamination in air and/or dust at school are less numerous (Cequier et al., 2014; Harrad et al., 2010; Lim et al., 2014; Mizouchi et al., 2015; Sofuoglu et al., 2010; Toms et al., 2015; Wallner et al., 2012; Wu et al., 2010) but they indicate that SVOCs are also present in school environments. It is important to gain better knowledge of SVOC contamination in school buildings. Indeed, though children spend nearly $70 \%$ of their time at home (Conrad et al., 2013; Zmirou et al., 2002), where they are 
exposed to SVOCs, they also spend $16 \%$ of their time at school (Zmirou et al., 2002) so the exposure to SVOCs within the school environment might also contribute to children's personal exposure. In this context, the French indoor air quality observatory (OQAI), already concerned about schools' indoor pollutants (Canha et al., 2015; Wei et al., 2015), decided to include the SVOC measurements in its nationwide survey involving 600 classrooms between 2013 and 2017. Ahead of this, a pilot study was necessary to develop an appropriate strategy for measuring SVOCs, using the most suitable sampling and analytical tools. During this exploratory phase, and without any prior knowledge of SVOC concentrations in French schools, several issues had to be faced - such as blank pollutions and suitability of the calibration range.

Nevertheless, the prime objective of this paper is to report the contamination levels of 55 SVOCs in the air and dust of 90 classrooms. These SVOCs had already been selected for their health interest (Bonvallot et al., 2010). They belong to several chemical families (organochlorines, organophosphates, pyrethroids, phosphoric ester, musks, PAHs, phthalates, PBDEs and PCBs) and were to be analyzed simultaneously, using a single analytical method. This study also presented an opportunity to compare two settled dust sampling methods - one using wipes, the other a vacuum cleaner. This comparison, carried out using a mass/surface unit for both types of sampling, aimed at selecting the more appropriate sampling method for the national campaign - though it was also of interest because it had not often been reported in the scientific literature.

\section{Materials and Methods}

School selection. Thirty schools located in Ille-et-Vilaine, Brittany, France, joined the study on a voluntary basis during the 2009-2010 academic year. There were 16 nursery schools (attended by children aged 2 to 5) and 14 primary schools (children aged 6 to 11). Further characteristics 
are described in supporting information (SI) (SI Table 1). Three classrooms were investigated in each school.

SVOC selection. SVOCs were selected using a ranking method based on toxicity and indoor exposure levels (Bonvallot et al., 2010). In short, data on settled dust concentrations in dwellings were collected with a literature review for 156 SVOCs. These concentrations were then compared to toxicity reference doses retrieved from toxicity databases or calculated from no observed effect levels (NOELs) (or lowest observed effect levels (LOELs)) and uncertainty factors. The topranked compounds were phthalates, pesticides, short-chain chlorinated paraffins, pentaBDEs (BDE-85, 99, 100 and 119), perfluorinated compounds, organotins, PCBs, and PAHs. Of these chemicals, we studied those which could be simultaneously analyzed using gas chromatography coupled with mass spectrometry (GC/MS). The final list of compounds included 55 SVOCs from 11 chemical classes: 12 organochlorines ( $\alpha$-endosulfan, $\alpha$-hexachlorocyclohexane $(\alpha-\mathrm{HCH}), \gamma$ hexachlorocyclohexane $(\gamma-\mathrm{HCH}$ also known as lindane), aldrin, cis-chlordane, dichlorodiphenyldichloroethylene (4,4'-DDE), dichlorodiphenyltrichloroethane (4,4'-DDT), dieldrin, endrin, heptachlor, metolachlor, and trans-chlordane), 3 organophosphates (diazinon, dichlorvos and chlorpyrifos), 1 triazine (atrazine), 1 oxadiazolone (oxadiazon), 5 pyrethroids (cyfluthrin, cypermethrin, deltamethrin, permethrin and tetramethrin), 1 phosphoric ester (tributylphosphate), 2 polycyclic musks (galaxolide and tonalide), 7 PAHs (acenaphtene, anthracene, benzo(a)pyrene, fluoranthene, fluorene, phenanthrene and pyrene), 11 PCBs (PCB 28, 31, 52, 77, 101, 105, 118, 126, 138, 153 and 180), 8 phthalates (bis(2-ethylhexyl)-phthalate (DEHP), butyl benzyl phthalate (BBP), di(methoxyethyl)-phthalate (DMEP), dibutyl-phthalate (DBP), diethyl phthalate (DEP), diisobutyl-phthalate (DiBP), diisononyl-phthalate (DiNP) and dimethyl-phthalate (DMP) and 4 PBDEs (BDE 85, 99, 100 and 119). 
Air Sampling. Air samples were collected on a $76 \mathrm{~mm}$ polyurethane foam (PUF) (SKC, Eighty Four, USA) that had previously been cleaned with dichloromethane (DCM) using pressurized liquid extraction (PLE) and inserted in a 22 x $100 \mathrm{~mm}$ glass tube (SKC, Eighty Four, USA). Particulate matter was collected on a $25 \mathrm{~mm}$ quartz fiber filter (QFF) (Whatman, Maidstone, Kent) fitted in front of the PUF. The air was pumped through the device using a GilAir-5 pump (Sensidyne, St. Petersburg, USA). The sampling device was installed in a position representative of the whole classroom, and if possible, in the middle of the room, away from emitting materials and drafts, and at the children's airway height $(1.30 \mathrm{~m})$. To avoid introducing potentially emitting materials to the classroom, silicone was chosen (for its inertness) for the tubing between the glass tube and the pump, while metallic laboratory clamps and holders were used to secure the sampling device in place. The pump was stored in a noise-insulated wooden box to avoid disturbing the occupants of the classroom. The air sampling method was inspired by Bouvier et al (2006). Air was sampled continuously for 4.5 days during a normal school week (from Monday morning to Friday afternoon) at $2 \mathrm{~L} / \mathrm{min}$, thus allowing about $12.6 \mathrm{~m}^{3}$ of air to be collected. The flow rate was checked before and after sampling with a Gilibrator 2 flowrate meter (Sensidyne, St. Petersburg, U.S.A). At the end of the sampling period, the sampling device was transported back to the laboratory in an icebox. The PUF and filters were then wrapped together in foil paper previously cleaned with $\mathrm{DCM}$ and stored at $-18^{\circ} \mathrm{C}$ in an amber glass vial for up to a month (Blanchard, 2001) prior to analysis. A field blank sample was taken for each investigated school (i.e. one field blank for 3 classrooms).

Dust sampling. To avoid any disturbance of air sampling, dust was sampled either during the week preceding air sampling or just after the end of air sampling. Two different methods were used for sampling settled dust. The first method consisted of vacuuming dust settled on the floor in a cellulose thimble using a modified vacuum cleaner. A 10 to $12 \mathrm{~m}^{2}$ area in which children 
spend most time was measured and vacuumed slowly (about $0.5 \mathrm{~m}^{2}$ per minute). This dust sampling method is fully described elsewhere (Blanchard et al., 2014) and in SI page 2. The second method consisted of collecting settled dust using a damp wipe on a $0.1 \mathrm{~m}^{2}$ square floor surface The floor area to be sampled was a smooth surface such as stone, wooden or plastic floor, chosen in an area where the children spend most time. Three wipes per classroom were collected and a sampling blank was made for each school investigated (i.e. one field blank for every 3 classrooms). This dust sampling method was adapted from elsewhere (Le Bot et al., 2010) and is also fully described in SI page 2.

Vacuumed dust preparation After collection, the content of each cellulose cartridge was passed through a pre-cleaned (DCM) $100 \mu \mathrm{m}$ sieve using a vibrating stainless steel sieve apparatus to remove coarse material (cotton and debris) and thus obtain a more homogeneous sample. The sieved dust was then weighed and stored at $-18^{\circ} \mathrm{C}$ in an amber glass flask hermetically sealed until chemical analysis (Blanchard et al., 2013).

Sample extraction and analysis. Full details on the reagents and chemicals used for analyses are provided in SI page 2. A detailed description of the extraction method for vacuumed dust and air samples, using pressurized liquid extraction, is already available elsewhere (Blanchard et al., 2014; Mercier et al., 2014) and is also provided in SI pages 3. For wiped dust, extraction was performed on $200 \mathrm{mg}$ of sieved dust. Wiped dust samples were defrosted (1 hour at room temperature in amber vials) then transferred into glass centrifuge tubes. After adding $8 \mathrm{~mL}$ of DCM and $100 \mathrm{ng}$ of each surrogate standard (fenpropathrin and methoprotryne), the tubes were centrifuged at $2000 \mathrm{rpm}$ for 2 minutes, then sonicated for 20 minutes at a temperature below $30^{\circ} \mathrm{C}$ and centrifuged again at $3000 \mathrm{rpm}$ for 5 minutes. After freezing the sample to separate the water released by the wipe from the solvent, $5 \mathrm{~mL}$ of the DCM extract were collected and mixed with the other two wipe extracts from the same classroom. The combined extract was then 
concentrated to $1 \mathrm{~mL}$, cleaned up on Chromabond® $\mathrm{NH} 2$ glass columns prewashed with $6 \mathrm{~mL}$ of DCM and eluted with $5 \mathrm{~mL}$ of DCM. After concentrating to $0.5 \mathrm{~mL}$ and adding $1 \mu \mathrm{g}$ of $2,3,4-$ trichloronitrobenzene (TCNB) as internal standard (ISTD), the final extract was stored at $-18^{\circ} \mathrm{C}$ prior to analysis. All extracts were then analyzed using gas chromatography coupled to tandem mass spectrometry. A detailed description of the analytical method is already available elsewhere (Mercier et al., 2014) and is also fully described in SI page 3.

Analysis of highly concentrated compounds. As little data about concentrations found in schools was available prior to this study, concentrations of several compounds appeared to exceed the top of the calibration range, and analyses of less concentrated extracts were needed. However, analyzing each sample twice or more would have exceeded the initial budget. Therefore, in an attempt to evaluate the SVOC concentrations above the upper limit (UL) of the calibration range, 7 extracts for air samples and 32 extracts for dust samples were diluted by a factor of 20 for air samples, up to 200 for vacuumed dust samples and up to 1000 for wiped dust samples. These extracts were chosen from those that needed dilution, and are therefore not representative. The calculated concentrations, presented in SI Tables 10, 11 and 12, were only used for dust sampling method comparison and as information for the upcoming nationwide survey. However, since the concentrations of BBP, DEHP and DiNP in vacuumed dust and BBP and DEHP in wiped dust were greater than UL in all the samples, results from the diluted extracts could be considered characteristic of the schools studied, and were used in this work.

Comparison between floor dust sampling methods. To compare the concentrations found in vacuumed dust and in wiped dust, the classrooms where vacuumed dust had been collected on a soft surface (such as carpets or rugs) were removed from the database because wiped dust was never sampled on such surfaces. Only those samples collected on hard surfaces were therefore considered for comparison. Regarding vacuumed dust, the total mass of sampled dust was 
weighed and the sampled surface was measured. Concentration in vacuumed dust in $\mathrm{ng} / \mathrm{m}^{2}$ could thus be calculated in order to compare concentrations using the same unit: concentration per surface $\left(n g / m^{2}\right)=$ concentration per mass $(n g / g) \times$ total mass $(g) /$ sampled surface $\left(m^{2}\right)$. The comparison was performed for the 14 compounds quantified at least 10 times in matching vacuumed and wiped dust samples (i.e. paired data from the same classroom). Greater than UL concentrations were not included in this comparison unless they belonged to the 32 extracts that were diluted.

Quality assurance and quality control. Limits of quantification (LOQs) were defined as the lowest concentration of a substance for which the relative standard deviation (RSD) of replicate analyses was lower than 20\% (González et al., 2014). Quadratic calibration curves were established for each compound by analyzing at least five calibration solutions ranging from LOQs to ULs. The values for LOQs and ULs for each matrix are displayed in SI Table 2. Compounds were quantified with TCNB as ISTD. Laboratory blank and quality control (QC) samples were extracted and analyzed in order to control contamination from all consumables and check for method accuracy. A detailed description of their preparation is provided in SI page 4. Field blank samples were extracted and analyzed like other samples. When either a field blank sample or a laboratory blank sample showed a concentration greater than $30 \%$ of the concentration found in the associated samples, the results in these samples were not validated and were removed from the data. Where the contamination was less than $30 \%$ of the concentration found in associated samples, the concentrations for these samples were reported without blank correction. Other conditions regarding data validation are detailed in SI page 4.

Air sampling conditions were tested with an evaluation of PUF retention capacity according to the French norm XP X 43-058 (AFNOR, 2007). A mix of 44 SVOCs was spiked onto the QFFs fitted in front of three clean PUFs, at a concentration greater than the maximum observed in 
samples. A second PUF was installed in series after one of the PUFs. Air was then sampled through the devices at $2 \mathrm{~L} / \mathrm{min}$ for 4.5 days. Air was also sampled in parallel through three clean, non-spiked, witness PUFs, with a second PUF in series for one of these. The recovery of each SVOC in the spiked devices was then assessed after correction by the concentration measured in the witness PUFs. According to the norm, the method is valid for a substance if it has a recovery between 60 and 120\%. PUFs in series were analyzed for substances not fitting these requirements.

Statistical analysis. Descriptive statistics of the data were produced using Excel Microsoft $^{\circledR}$ Office). In order to be able to rank the values for the calculation of percentiles, concentrations below the LOQ were assigned a value of $\mathrm{LOQ} / 2$ and concentrations above the UL of the calibration range were assigned a value equal to UL. This practice has an impact on percentiles: for example, if more than $5 \%$ of values are $>$ UL then the $95^{\text {th }}$ percentile and any above will be $>$ UL. Percentiles were therefore described as "> UL" where relevant in Table 1 and in SI Tables 6 to 9. Spearman rank correlation was used to test the association between SVOC levels in each type of dust (error rate of 5\%). (XL STAT ${ }^{\circledR}$ software). Boxplots were represented graphically by GraphPad Prism version 5.01 for Windows, GraphPad Software, San Diego California USA, http://www.graphpad.com.

\section{Results}

Field blank samples for air \& wiped dust. In air samples, five phthalates (BBP, DEHP, DMP, DiNP and DEP) were present in field blank samples at various concentrations. DiNP was most frequently detected, resulting in the cancellation of 32 results. For the other phthalates, 5 to 7 results could not be validated. Insufficient cleaning of the polyurethane foam was suspected to be the source of DiNP contamination, and this was addressed in subsequent works (Blanchard et al., 2014). Field blank wipe samples were also affected by phthalate contamination: BBP, DBP, 
DEHP, DiNP, DEP, DiBP and DMP were found in 2 to 10 samples, (depending on the molecule) and this caused the cancellation of 36 results, for which an obvious source has yet to be clearly identified.

Evaluation of the air sampling method. As shown in SI Table 3, recoveries were within $60 \%$ and $120 \%$ for 38 out of 44 compounds. Of these 38 compounds, the lowest recovery was observed for diazinon (66\%), whereas all other recoveries were between 80 and $110 \%$. For these compounds and for a 4.5 day sampling at $2 \mathrm{~L} / \mathrm{min}$, PUF retention capacities were $\geq 200 \mathrm{ng}$ for PCBs and certain pesticides, $\geq 500$ ng for pyrethroids, PAHs, PBDEs and other pesticides, $\geq 2.5 \mu \mathrm{g}$ for tributylphosphate, $\geq 10 \mu \mathrm{g}$ for musks and $\geq 100 \mu \mathrm{g}$ for phthalates. However, null or poor recoveries were observed for aldrin (0\%), dichlorvos (13\%), tetramethrin (0\%), acenaphthene (8\%), anthracene (37\%) and benzo(a)pyrene $(1 \%)$. The conditions of this test were those of a worst case scenario, as the whole substance was present at the beginning of the sampling period and would therefore have 4.5 days to reach its breakthrough volume or suffer from degradation - whereas in real conditions, substances would be caught on the PUF throughout the sampling period and might not reach their breakthrough volume or have time to be degraded. Nevertheless, concentrations reported in this work for these six compounds could not be validated and were removed from the reported results (Table 1 and SI Table $6 \& 7$ ).

SVOC concentrations in air QC samples and SRM 2585. Concentrations and associated RSD and recovery data were satisfactory as presented in SI pages $4 \& 5$ and summarized in SI Tables 4 and 5 .

SVOC concentrations in air. Of the 90 classrooms investigated, 84 air samples were kept for analysis. The remaining six were not analyzed because the sampled air volume was less than $90 \%$ of the expected volume of $12.6 \mathrm{~m}^{3}$. For the first 22 extracts analyzed, the concentration of several compounds - particularly musks and several phthalates - could not be evaluated because they 
were very often above the UL of the calibration range, and so were not reported in the final results. An upper concentration level was added to the calibration range for the remaining 62 samples. For these 62 samples, the results of the most frequently quantified substances are displayed in Table 1 while results for all substances can be seen in SI Table $6 \&$ 7. Of the 55 compounds analyzed, 33 were quantified at least once while 22 were never quantified (cischlordane, trans-chlordane, 4,4'-DDE, heptachlor, PCB 77, 105, 118, 126, 138, 153 and 180, 4,4'DDT, endrin, metolachlor, atrazine, oxadiazon, cyfluthrin, deltamethrin, tetramethrin, benzo(a)pyrene and BDE 85 and 119). The concentration of most of the compounds was in the calibration range with the exception of eight (galaxolide, tonalide, phenanthrene, DMP, DiBP, DBP, BBP and DEHP). The highest concentrations (median $>50 \mathrm{ng} / \mathrm{m}^{3}$ ) were measured for four phthalates (DiBP, DBP, DEP, and DEHP) and one musk (galaxolide). Intermediate concentrations (median from 1 to $40 \mathrm{ng} / \mathrm{m}^{3}$ ) were measured for DiNP, tonalide, BBP, DMP, phenanthrene, fluorene, tributylphosphate, $\gamma-\mathrm{HCH}$ and acenaphthene, in decreasing order of concentration. Seven compounds were only found in $10 \%$ to $30 \%$ of the samples (fluoranthene, a-HCH, PCB28, pyrene, PCB 52, PCB31 and BDE 99).

SVOC concentrations in vacuumed settled dust. Of the 55 compounds analyzed, 42 were quantified at least once and 13 were never quantified (cis-chlordane, aldrin, heptachlor, metolachlor, dichlorvos, cyfluthrin, deltamethrin, tetramethrin, atrazine, PCB 126, acenaphthene and BDE 85 and 119). Results of the most frequently quantified substances are displayed in Table 1, and all results can be seen in SI Tables $6 \& 8$. Greater than $30 \mu \mathrm{g} / \mathrm{g}$ median concentrations were reached for DEHP, DiNP and DiBP (> $50 \mu \mathrm{g} / \mathrm{g})$ and DBP $(36 \mu \mathrm{g} / \mathrm{g})$. The median concentrations measured for 10 compounds (BBP, DEP, galaxolide, phenanthrene, tonalide, pyrene, permethrin, DMP, fluoranthene and tributylphosphate) ranged from 0.1 to more 
than $3 \mu \mathrm{g} / \mathrm{g}$. Eight compounds were only quantified in $10 \%$ to $40 \%$ of the samples (fluorene, anthracene, benzo(a)pyrene, $\gamma$-HCH, 4,4'-DDT, PCB 101, BDE99 and PCB 138).

SVOC concentrations in wiped settled dust. Of the 55 compounds analyzed, 34 were quantified at least once while 21 were never quantified (cis-chlordane, trans-chlordane, 4,4'DDE, aldrin, endrin, heptachlor, metolachlor, dichlorvos, diazinon, cyfluthrin, deltamethrin, tetramethrin, atrazine, acenaphthene, PCB 28, 31, 77, 126 and 180, and BDE 85 and 119). Results of the most frequently quantified substances are displayed in Table 1 and all results can be seen in SI Table $6 \& 9$. Greater than $2 \mu \mathrm{g} / \mathrm{m}^{2}$ median concentrations were reached for DEHP, BBP, DiNP and DiBP (> $\left.33 \mu \mathrm{g} / \mathrm{m}^{2}\right)$, and DBP $\left(15 \mu \mathrm{g} / \mathrm{m}^{2}\right)$. The median concentrations measured for musks and DEP ranged from 0.2 to $1.5 \mu \mathrm{g} / \mathrm{m}^{2}$. Six compounds (phenanthrene, pyrene, DMP, fluoranthene, permethrin and tributylphosphate) were only found in 10 to $45 \%$ of the samples.

SVOC concentrations in vacuumed dust vs. wiped dust. Frequencies of quantification for the 14 compounds quantified more than 10 times in paired dust samples are shown in Table 2. These were higher in vacuumed dust than in wiped dust, except in the case of 5 phthalates (DiBP, DBP, BBP, DEHP and DiNP) found in $100 \%$ of the samples with both methods. Figure 1 shows the distribution of SVOC concentrations in vacuumed dust and wiped dust for these 14 compounds: concentrations measured in wiped dust were always larger than in vacuumed dust by a factor of 9 to 26 (ratio of the medians shown in Table 2).

Concentrations measured in the same room with both sampling methods were compared for each individual substance using Spearman correlation coefficients. These coefficients are summarized in Table 2. Significant correlations were observed for tonalide, fluoranthene, pyrene, DEHP, DiBP, DiNP DBP and galaxolide $(\mathrm{p}<0.05)$. No significant correlations were observed for permethrin, tributylphosphate, phenanthrene, BBP, DEP and DMP.

\section{Discussion}


SVOC selection. The ranking method used for the selection of SVOCs was preliminary based on dust contamination in dwellings, so SVOCs present in products having specific uses in schools may have been missed. However, the selection of SVOCs was initially based on a bibliographic search, then extended using expert judgement, so that the number of compounds potentially not included would be limited - as proven by the large number of SVOCs ultimately included in the ranking $(\mathrm{n}=156)$. Nevertheless, the differences in the contamination levels between schools and dwellings may have constituted a limit to this exercise because SVOCs may have ended up being differently ranked, had contamination in schools been considered. This limit was reduced by the choice of the analytical method allowing measurement of 55 compounds, rather than just those SVOCs that were initially sorted. Moreover, it was useful to measure the same compounds in schools and dwellings since this helped compare the profiles of SVOC contamination in different indoor environments.

Analytical method. The analysis of 55 target compounds from different chemical classes does present an analytical challenge. Most methods previously published were dedicated to the analysis of a specific family of compounds, whereas multi-residue analytical methods were rarely reported (Mercier et al., 2014). However, the ultimate goal of the method development was to be able to analyze hundreds of samples within a nationwide survey. This is why the multi-residue approach was adopted, entailing compromises between analytical performance and the constraints that are inherent to large scale studies, such as environmental sampling issues (e.g. limited availability of daily dust samples) and economic viability. As described by Mercier et al. (2014), these compromises were achieved by (i) the choice to use only PUF for air sampling without any resin adsorbents, which are more expensive and require more complex extraction procedures, (ii) automation of the extraction procedure, (iii) simplification of the clean-up procedure, (iv) the use of native rather than labelled surrogate standards and (v) the use of tandem 
mass spectrometry for its selectivity and sensitivity. The laboratory obtained Cofrac (French Committee for Accreditation) accreditation in accordance with the ISO/CEI 17025 standard for this method.

Our LOQs, however, were relatively high for 4 chemical families (organochlorines, organophosphates, PCBs and PBDEs). In air (SI Table 13), Wilson et al. (2003), Lim et al. (2014) and Bradman et al. (2014) reported concentrations below our LOQ for PBDEs. In dust (SI Table 14), concentrations lower than our LOQ were also reported by Wilson et al. (2003), Dalvie et al. (2014), and Harrad et al.(2010). LOQs are often based on the signal-to-noise (S/N) ratio approach. This approach was impractical with our system, because smoothing was applied to the signal, making $\mathrm{S} / \mathrm{N}$ ratios meaningless. The standard deviation approach, described by González et al. (2014) was used instead, making comparison with other studies more difficult. However, these higher LOQs might also be a consequence of our multiresidue approach, and would probably have been lower using dedicated methods. Nevertheless, the multi-residue method allowed for the simultaneous analysis of multiple compounds in an economically sound way while still providing valuable information about the relative presence of SVOCs in classrooms.

Evaluation of air sampling method. Tested concentrations were greater than the highest concentrations reported in samples and showed that the air sampling method was fit for purpose, except for the six compounds for which null or poor recoveries were observed. The hypothesis of a low breakthrough volume was verified on acenaphthene for which $4 \%$ of the spiked amount was measured in the second, in series, PUF (SI Table 3). However for aldrin, dichlorvos, tetramethrin, anthracene and benzo(a)pyrene, the amount left in the second PUF was null, which means that these molecules are probably also subject to degradation. During the 4.5 days sampling period, PUFs were only kept in their glass cartridge and were therefore exposed to sunlight and variations of room temperature. Photolysis has indeed been reported, for example for 
aldrin (Burrows et al., 2002), tetramethrin (US EPA, 2010) and benzo(a)pyrene (Zhang et al., 2006).

Contamination levels of SVOCs in schools. The data presented in this study were compared to other studies reported in scientific literature from 2003 to 2015, including studies in primary or elementary schools and in nursery schools and daycare centers where the children's age matched those attending French nursery schools (2-5 years old). Summaries of these comparisons are available in Supporting Information (SI Table $13 \&$ 14). These summaries mention the sampling techniques used, since SVOC concentrations can only be compared if sampled in a similar manner. Sampling for the present study was conducted from November 2009 to June 2010, covering three seasons (autumn, winter and spring). Ambient and indoor meteorological conditions were not monitored in this study, although these would affect SVOC emissions (Clausen et al., 2012; Wu et al., 2016). Likewise, seasonal effects on SVOC emissions were reported (Cao et al., 2014). Moreover, the choice of dust fraction to be analyzed is also important, as SVOC concentrations vary significantly with particle size: in general, concentration of toxic chemicals in dust increases as particle size decreases (Cao et al., 2012; Mercier et al., 2011). Cao et al. also emphasize that dust with particle size less than $100 \mu \mathrm{m}$, which we chose, should be paid more attention because it is more relevant to human exposure. Sieved fractions between 63 $\mu \mathrm{m}$ to $500 \mu \mathrm{m}$ were reported in the literature relating to SVOCs in schools (Bradman et al., 2014; Clausen et al., 2003; Gaspar et al., 2014; Harrad et al., 2010; Mizouchi et al., 2015; Wallner et al., 2012; Wilson et al., 2003). Sometimes larger particles and sand deposits were removed but the dust was not sieved (Fromme et al., 2013, 2014). Nevertheless, the number of studies in schools was limited so different sampling conditions and dust particle size fractions were considered even though this constitutes a limitation of the comparison of our results with the literature. 
In air (SI Table 13), in comparison with other studies, concentrations measured in these 30 French schools were always similar or slightly lower than what had been observed elsewhere, except DiBP which was more concentrated in our study (> $800 \mathrm{ng} / \mathrm{g}$ ) than in that of Fromme et al. (2013) (468 ng/g) or Gaspar et al. (2014) (100 ng/g). Such a discrepancy was also observed in French dwellings (Blanchard et al., 2014) and could be explained by the gradual substitution of DBP by DiBP.

In dust, Morgan et al. (2007) used wipes to sample dust settled on the floor in Ohio daycare centers. They reported $140 \mathrm{ng} / \mathrm{m}^{2}$ of (cis + trans) permethrin which is more than reported in the present study $\left(<40 \mathrm{ng} / \mathrm{m}^{2}\right)$. This higher level was confirmed in vacuumed dust $(1554 \mathrm{ng} / \mathrm{g}$ vs. 279 ng/g). Regarding other compounds in vacuumed dust (SI Table 14), PAH concentrations were of the same order as in North Carolina, USA: phenanthrene, fluoranthene and pyrene concentrations were 338, 437 and 354 ng/g respectively (Wilson et al., 2003), vs. 363, 184 and $285 \mathrm{ng} / \mathrm{g}$ respectively, in this study. A slightly lower concentration of $98 \mathrm{ng} / \mathrm{g}$ was measured for pyrene in Denmark (Langer et al., 2010). In all studies, phthalates, and particularly DEHP and DiNP, are found in higher concentrations than other substances. Medians found for DEP, DBP, DEHP and DiNP in our study are within the range of other studies: DEP, measured at $2.89 \mu \mathrm{g} / \mathrm{g}$ in this study, is at most twice as concentrated as in Denmark $(2.20 \mu \mathrm{g} / \mathrm{g})$, Germany or California, USA $(1.40 \mu \mathrm{g} / \mathrm{g}$ for both); the range of concentrations for DBP, measured at $38.2 \mu \mathrm{g} / \mathrm{g}$ in this study go from $1.87 \mu \mathrm{g} / \mathrm{g}$ (North Carolina, USA) to $52.0 \mu \mathrm{g} / \mathrm{g}$ (South Korea); likewise, DEHP and DiNP respectively quantified at $1430 \mu \mathrm{g} / \mathrm{g}$ and $1030 \mu \mathrm{g} / \mathrm{g}$ in this study are within the range of other studies (from $172 \mu \mathrm{g} / \mathrm{g}$ in California, USA to $3350 \mu \mathrm{g} / \mathrm{g}$ in Austria for DEHP and from 302 $\mu \mathrm{g} / \mathrm{g}$ in Germany to $946 \mu \mathrm{g} / \mathrm{g}$ in South Korea for DiNP). However, DiBP and BBP were at least twice as concentrated in French schools: the median concentration for DiBP, greater than $52 \mu \mathrm{g} / \mathrm{g}$ is higher than in Denmark $(23 \mu \mathrm{g} / \mathrm{g})$, Germany $(20 \mu / \mathrm{g})$ or California, USA $(9.3 \mu \mathrm{g} / \mathrm{g})$; the French 
concentration for BBP $(105 \mu \mathrm{g} / \mathrm{g}$ ) was also higher than in other studies, ranging from 3.72 (North Carolina, USA) to $46.8 \mu / \mathrm{g}$ (California, USA) (Clausen et al., 2003; Fromme et al., 2013; Gaspar et al., 2014; Hutter et al., 2013; Kim et al., 2013; Langer et al., 2010; Wallner et al., 2012; Wilson et al., 2003). The frequent presence of PVC flooring (in $70 \%$ of classrooms) could explain the higher concentration of BBP in school dust, since more than $70 \%$ of BBP produced is used as a plasticizer in polymer products, mainly PVC for flooring (ECHA, 2009). The presence of DiBP might be related to its use in such children's products as crayons, erasers and school bags (ECHA, 2010).

Our results were compared to 2 others French surveys that investigated a similar list of compounds: Blanchard et al. (2014) investigated air and dust in 30 dwellings in Brittany, using similar sampling techniques and the same analytical method and Mandin et al. (Mandin et al., 2013) measured SVOCs in 145 dust samples from household vacuum cleaners using the same (albeit more sensitive) analytical method. In air, compared to the 30 dwellings, concentrations found in schools are up to twice as high for tributylphosphate, musks, PAHs and phthalates except BBP which is about eight times more concentrated in schools than in dwellings. Concentrations found in dust are similar for tributylphosphate, musks, PAHs, and the three lessconcentrated phthalates (DMP, DEP and DMEP). However, the other phthalates are more concentrated in schools by factors of around three (DiBP, DBP), five (DEHP), eight (DiNP) and twelve (BBP). Langer et al. (2010) compared phthalate and PAH contamination in homes and day care centers. They found that with the exception of DEP, concentrations of phthalates in dust were higher in daycare centers than in homes, whereas PAH concentrations were similar, confirming our observations in schools and pre-schools.

Sources of phthalates include personal care products and cosmetics, PVC flexible pipe, PVC flooring, wall covering, etc. (Mercier et al., 2011). In nursery schools, Kim et al. (2013) found 
that DEHP concentrations correlated significantly with the area of PVC flooring. DiNP probably follows the same trend, as it started replacing DEHP, as well as DBP and BBP, in response to the restriction of their use in Europe (Blanchard et al., 2014). Descriptions of French dwellings available on the OQAI website (www.oqai.fr) show the presence of PVC or linoleum flooring in 18 to $26 \%$ of rooms, vs $60 \%$ of classrooms at a national level (70\% in this study) for PVC flooring only. This supports the hypothesis that higher phthalate concentrations in schools might be associated with the presence of PVC flooring, either because of the material itself or because of the application of floor care chemical products (Bi et al., 2015). Children's higher exposure to DiBP, DBP, BBP, DEHP and DiNP at school compared to at home should thus be considered in both risk assessments and epidemiological studies, as it may contribute substantially to exposure.

Comparison of vacuum and wipe sampling methods and results. The wipe sampling method is easy to implement, silent and fast (less than 10 minutes per classroom) whereas the vacuum cleaner sampling method requires more preparation, is slower (about 20 minutes per classroom) and noisy. In addition, a recurrent issue that occurred in this study and was also observed by Kim et al. (2013) and Harrad et al. (2010), was the lack of dust for vacuuming. In general, classrooms are cleaned on a daily basis, so reaching the mass of dust necessary for analysis meant sampling large areas and organizing the sampling according to the school cleaning schedule, which sometimes could not be achieved.

More compounds can be quantified using the vacuum cleaner, which is inherent to the sampling method: LOQs were based on analysis of $200 \mathrm{mg}$ of dust when available, or 3 wipes. The median quantity of dust sampled with a wipe is $30 \mathrm{mg}$ (Le Bot et al., 2010) (i.e. $90 \mathrm{mg}$ for 3 wipes) so the LOQs in wipes were often more than double those in vacuumed dust. However, concentrations measured in wiped dust were higher than in vacuumed dust. Several hypotheses may explain this difference. First, as shown by Cettier et al. (2015) for the collection of PCBs and 
pesticides, wipe sampling is efficient, particularly in the presence of dust. Indeed wipe sampling allows the thorough collection of all dust present on the floor, including fine and large particles, since the wipe's moisture can help unstick stuck dust or collect SVOCs released by the surface of the floor material. Second, the fraction collected with the vacuum cleaner misses those fine and large particles, since the finest pass through the cellulose thimble or are stuck in it and the largest (fraction greater than $100 \mu \mathrm{m}$ ) are eliminated through the sieving process. Third, the depression created by the vacuum cleaner may disturb the partitioning of the molecules between gas phase and dust, possibly according to their volatility. These hypotheses may explain the absence of significant correlation between the two sampling methods for permethrin, tributylphosphate, phenanthrene, BBP, DEP and DMP as the dust composition may have differed between classrooms.

In the past ten years, sampling involving both vacuuming and wiping methods have been described in scientific literature: Watkins et al. (2013) measured PBDEs in office air, vacuumed dust and surface wipes and observed a significant correlation between BDE 209 in dust and in surface wipes $(\mathrm{r}=0.69, \mathrm{p}=0.007)$, although their methodology was different to ours; the surface wipes were sampled on undisturbed "dusty" surfaces such as bookshelves or filing cabinets. In addition they compared concentrations in mass per mass for dust versus mass per surface for wipes. Wu et al. (2010) found significant correlations between floor dust (in $\mathrm{ng} / \mathrm{g}$ ) and surface dust (in $\mathrm{pg} / \mathrm{cm}^{2}$ ) for BDE 183, 100 and 99, but not for the other PBDEs. Morgan et al. (2007) measured pyrethroid concentrations in dust and hard floor surface wipes but again these concentrations cannot be compared due to different concentration units (ng/g vs. $\mathrm{ng} / \mathrm{cm}^{2}$ ). Wason et al. (2013) studied correlations of organophosphate and pyrethroid concentrations between dust and kitchen or living room floor wipes, still in inhomogeneous units, in which diazinon, chlorpyrifos, permethrin and cyfluthrin showed significant correlations, at least for kitchen wipes, 
whereas no significant correlation was established for cypermethrin. Comparisons between vacuumed and wiped dust using a homogeneous unit (mass/surface) are rarely performed despite the usefulness of considering dust contamination, not only in ng/g of a specific sieved fraction, but also in $\mathrm{ng} / \mathrm{m}^{2}$. Both types of dust sampling have been shown to be useful to characterize human exposure to dust. The wipe method represents surface loading and as Lioy et al (2002) explained, it can be used to estimate the amount of material available on a surface and the amount available for contact by a person. It was designed and used to imitate the hand's ability to pick up and retain particles (Le Bot et al., 2010) so wiped dust seems suitable for the evaluation of children's exposure. Vacuumed dust provides more knowledge in terms of dust contamination and is useful to characterize potential sources inside or outside a home (Lioy et al., 2002), yet can also be used as a proxy of dust exposure: Meeker et al. (2013) showed that some organophosphate flame retardants in vacuumed house dust were related to human urinary metabolites; Bennett et al. (2014) showed that PBDEs, not only in floor wipes but also in vacuumed dust, were correlated with serum levels.

\section{Conclusion}

This study which presents the contamination levels of SVOCs in schools for the first time in France has certain limitations relating to relatively high LOQs for some substances, the lack of data above the upper limit of the calibration range, the as yet unresolved issue of contaminated wipe blanks and the occasional difficulty vacuuming enough dust. Furthermore, the glass cartridges used for air sampling might not be suitable for the analysis of photosensitive compounds. Some of these limitations could be overcome: for example the mass of vacuumed dust could be maximized with well-timed dust sampling performed before any scheduled housekeeping and allowing enough time to sample a large floor surface; alternatively, an extraction technique such as thermal desorption, requiring less dust, could be developed; air 
could be sampled using a lightproof device; LOQs could be lowered using a last generation, more sensitive, detector or with an increase of the injection volume. Nevertheless, the multi-residue method allows simultaneous analysis of multiple compounds in an economically sound way while still providing valuable information about the relative presence of SVOCs in classrooms. This shows in particular that DiBP, DBP, BBP, DEHP and DiNP in dust are found more frequently in schools than in homes. These findings suggest that school exposure is not negligible for phthalates, demanding further investigation since the exposure would be underestimated in this work as a result of the lack of data above ULs. The comparison carried out between dust sampling with wipes, or with a vacuum cleaner, was for the first time reported using the same unit $\left(\mathrm{ng} / \mathrm{m}^{2}\right)$ and shows that sampling technique has an impact on SVOC measurement in dust: dust sampling allows more compounds to be measured whereas wipe sampling leads to greater concentrations. The choice of the sampling method should of course be objective driven and consider the practical implementation and contamination levels. The use of vacuumed dust could be favored when the concentrations are too low to be quantified with the wipe method. 
Figure 1. SVOC concentrations in vacuumed and wiped dust for substances quantified in matched samples

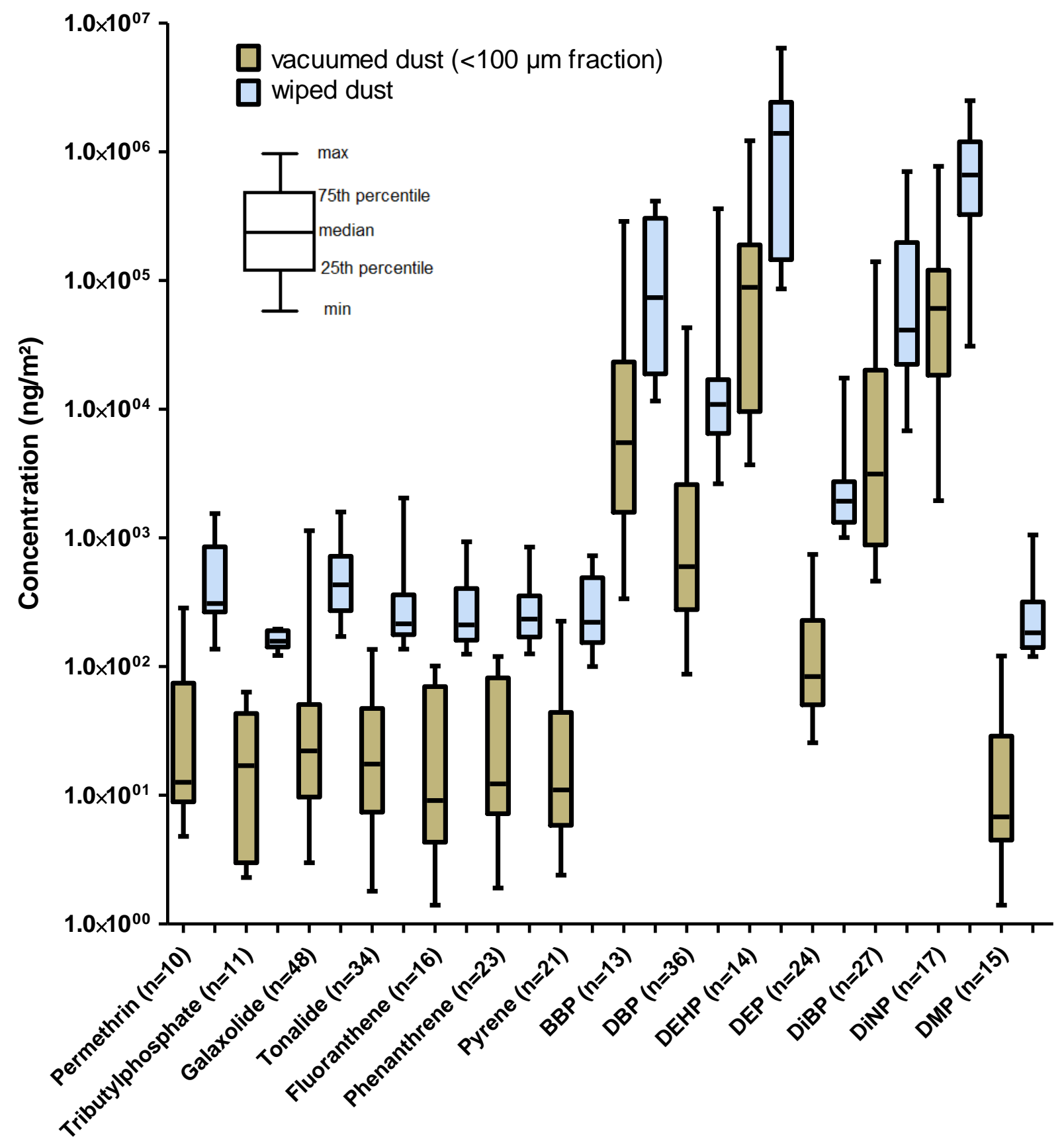


Table 1. SVOC concentrations in French classrooms (Brittany, France, 2010)

\begin{tabular}{|c|c|c|c|c|c|c|c|c|c|c|c|c|c|c|c|c|c|c|c|c|c|}
\hline \multirow[b]{2}{*}{$\begin{array}{l}\text { Substance } \\
\text { Organochlorinated } \\
\text { pesticides: }\end{array}$} & \multicolumn{7}{|c|}{$\operatorname{Air}\left(\mathbf{n g} / \mathrm{m}^{3}\right)$} & \multicolumn{7}{|c|}{ Vacuumed dust $(<100 \mu \mathrm{m}$ fraction) $(\mathrm{ng} / \mathrm{g})$} & \multicolumn{5}{|c|}{ Wiped dust $\left(\mathrm{ng} / \mathrm{m}^{2}\right)$} & \multirow[b]{2}{*}{ 95th\% } & \multirow[b]{2}{*}{$\mathbf{F}$} \\
\hline & LOQ & UL & $\mathbf{N}$ & 5th\% & 50th\% & 95th\% & $\mathbf{F}$ & LOQ & UL & $\mathbf{N}$ & 5 th $\%$ & 50th\% & 95th\% & $\mathbf{F}$ & LOQ & UL & $\mathbf{N}$ & 5 th\% & 50th\% & & \\
\hline$\alpha-\mathrm{HCH}$ & 0.4 & 20 & 59 & $<0.4$ & $<0.4$ & 3.4 & $24 \%$ & 26 & 1320 & 89 & $<26.3$ & $<26.3$ & $<26.3$ & $2 \%$ & 20 & 830 & 81 & $<20$ & $<20$ & $<20$ & $1 \%$ \\
\hline$\gamma-\mathrm{HCH}$ & 1.0 & 50 & 62 & $<1.0$ & 2.0 & 7.2 & $79 \%$ & 66 & 3290 & 89 & $<65.8$ & $<65.8$ & 247 & $18 \%$ & 40 & 2080 & 81 & $<40$ & $<40$ & $<40$ & $4 \%$ \\
\hline 4,4'-DDT & 1.0 & 50 & 62 & $<1.0$ & $<1.0$ & $<1.0$ & $0 \%$ & 66 & 3290 & 89 & $<65.8$ & $<65.8$ & 177 & $15 \%$ & 40 & 2080 & 81 & $<40$ & $<40$ & $<40$ & $2 \%$ \\
\hline $\begin{array}{l}\text { Pyrethroids: } \\
\text { Permethrin }\end{array}$ & 1.0 & 50 & 62 & $<1.0$ & $<1.0$ & $<1.0$ & $2 \%$ & 66 & 3290 & 89 & $<65.8$ & 279 & 1961 & $61 \%$ & 40 & 2080 & 81 & $<40$ & $<40$ & 578 & $27 \%$ \\
\hline $\begin{array}{l}\text { Phosphoric ester: } \\
\text { Tributylphosphate }\end{array}$ & 1.0 & 50 & 62 & 2.0 & 4.7 & 12.4 & $100 \%$ & 66 & 3290 & 89 & $<65.8$ & 103 & 401 & $74 \%$ & 40 & 2080 & 79 & $<40$ & $<40$ & 190 & $20 \%$ \\
\hline $\begin{array}{l}\text { Musks: } \\
\text { Galaxolide }\end{array}$ & 1.0 & 50 & 62 & 46 & $>50$ & $>50$ & $100 \%$ & 66 & 3290 & 89 & 304 & 965 & 2191 & $98 \%$ & 40 & 2080 & 65 & 148 & 335 & 1213 & $97 \%$ \\
\hline Tonalide & 1.0 & 50 & 62 & 10 & 20 & $>50$ & $100 \%$ & 66 & 3290 & 89 & $<65.8$ & 337 & 915 & $88 \%$ & 40 & 2080 & 81 & $<40$ & 170 & 642 & $63 \%$ \\
\hline $\begin{array}{l}\text { PAHs: } \\
\text { Acenaphtene }\end{array}$ & 1.0 & 50 & 62 & $*$ & $*$ & * & $53 \%$ & 66 & 3290 & 89 & $<65.8$ & $<65.8$ & $<65.8$ & $0 \%$ & 40 & 2080 & 81 & $<40$ & $<40$ & $<40$ & $0 \%$ \\
\hline Fluorene & 1.0 & 50 & 62 & 2.5 & 5.5 & 13 & $100 \%$ & 66 & 3290 & 89 & $<65.8$ & $<65.8$ & 268 & $40 \%$ & 40 & 2080 & 81 & $<40$ & $<40$ & 175 & $9 \%$ \\
\hline Phenanthrene & 1.0 & 50 & 62 & 4.8 & 8.7 & 18 & $100 \%$ & 66 & 3290 & 89 & $<65.8$ & 363 & 907 & $92 \%$ & 40 & 2080 & 75 & $<40$ & $<40$ & 539 & $45 \%$ \\
\hline Anthracene & 1.0 & 50 & 62 & $*$ & $*$ & $*$ & $2 \%$ & 66 & 3290 & 89 & $<65.8$ & $<65.8$ & 127 & $40 \%$ & 40 & 2080 & 81 & $<40$ & $<40$ & $<40$ & $1 \%$ \\
\hline Fluoranthene & 1.0 & 50 & 62 & $<1.0$ & $<1.0$ & 1.6 & $29 \%$ & 66 & 3290 & 89 & $<65.8$ & 184 & 751 & $85 \%$ & 40 & 2080 & 81 & $<40$ & $<40$ & 441 & $32 \%$ \\
\hline Pyrene & 1.0 & 50 & 62 & $<1.0$ & $<1.0$ & 1.2 & $18 \%$ & 66 & 3290 & 89 & $<65.8$ & 285 & 760 & $90 \%$ & 40 & 2080 & 80 & $<40$ & $<40$ & 525 & $40 \%$ \\
\hline Benzo(a)pyrene & 1.0 & 50 & 62 & $*$ & $*$ & $*$ & $0 \%$ & 66 & 3290 & 89 & $<65.8$ & $<65.8$ & 172 & $27 \%$ & 40 & 2080 & 81 & $<40$ & $<40$ & 125 & $6 \%$ \\
\hline $\begin{array}{l}\text { PCBs: } \\
\text { PCB } 31\end{array}$ & 0.4 & 20 & 62 & $<0.4$ & $<0.4$ & 0.6 & $15 \%$ & 26 & 1320 & 89 & $<26.3$ & $<26.3$ & $<26.3$ & $2 \%$ & 20 & 830 & 81 & $<20$ & $<20$ & $<20$ & $0 \%$ \\
\hline РСВ 28 & 0.4 & 20 & 62 & $<0.4$ & $<0.4$ & 0.9 & $19 \%$ & 26 & 1320 & 89 & $<26.3$ & $<26.3$ & $<26.3$ & $6 \%$ & 20 & 830 & 81 & $<20$ & $<20$ & $<20$ & $0 \%$ \\
\hline РCB 52 & 0.4 & 20 & 62 & $<0.4$ & $<0.4$ & 0.5 & $16 \%$ & 26 & 1320 & 89 & $<26.3$ & $<26.3$ & 48 & $7 \%$ & 20 & 830 & 81 & $<20$ & $<20$ & $<20$ & $2 \%$ \\
\hline PCB 101 & 0.4 & 20 & 62 & $<0.4$ & $<0.4$ & $<0.4$ & $2 \%$ & 26 & 1320 & 89 & $<26.3$ & $<26.3$ & 107 & $13 \%$ & 20 & 830 & 81 & $<20$ & $<20$ & $<20$ & $1 \%$ \\
\hline PCB 138 & 0.4 & 20 & 62 & $<0.4$ & $<0.4$ & $<0.4$ & $0 \%$ & 26 & 1320 & 89 & $<26.3$ & $<26.3$ & 79 & $10 \%$ & 20 & 830 & 81 & $<20$ & $<20$ & $<20$ & $1 \%$ \\
\hline Phthalates: & & & & & & & & & & & & & & & & & & & & & \\
\hline DMP & 1.0 & 50 & 53 & 6.7 & 13 & $>50$ & $100 \%$ & 66 & 3290 & 54 & $<65.8$ & 252 & 1680 & $87 \%$ & 40 & 2080 & 79 & $<40$ & $<40$ & 555 & $39 \%$ \\
\hline DEP & 8.0 & 800 & 53 & 85 & 221 & 515 & $100 \%$ & 526 & 52600 & 76 & 739 & 2890 & 6560 & $93 \%$ & 333 & 33300 & 65 & $<333$ & 1310 & 5200 & $66 \%$ \\
\hline DiBP & 8.0 & 800 & 62 & 352 & $>800$ & $>800$ & $100 \%$ & 526 & 52600 & 89 & 41000 & $>52600$ & $>52600$ & $100 \%$ & 333 & 33300 & 71 & 11000 & $>33300$ & $>33300$ & $100 \%$ \\
\hline DBP & 8.0 & 800 & 62 & 66 & 228 & 744 & $100 \%$ & 526 & 52600 & 89 & 11000 & 38200 & $>52600$ & $100 \%$ & 333 & 33300 & 64 & 4220 & 15200 & $>33300$ & $100 \%$ \\
\hline $\mathrm{BBP}^{\mathrm{ab}}$ & 1.0 & 50 & 56 & 3.7 & 19 & $>50$ & $100 \%$ & 66 & 3290 & 22 & 11400 & 105000 & 468000 & $100 \%$ & 40 & 2080 & 22 & 6750 & 73600 & 1940000 & $100 \%$ \\
\hline DEHP ${ }^{\mathrm{ab}}$ & 8.0 & 800 & 58 & 49 & 108 & 417 & $100 \%$ & 526 & 52600 & 28 & 275000 & 1430000 & 5830000 & $100 \%$ & 333 & 33300 & 28 & 86900 & 1210000 & 4520000 & $100 \%$ \\
\hline DiNP $^{a}$ & 8.0 & 800 & 30 & 8.2 & 35 & 214 & $93 \%$ & 526 & 52600 & 32 & 258000 & 1030000 & 4100000 & $100 \%$ & 333 & 33300 & 77 & 33000 & $>33300$ & $>33300$ & $100 \%$ \\
\hline PBDEs: & & & & & & & & & & & & & & & & & & & & & \\
\hline BDE 99 & 1.0 & 50 & 62 & $<1.0$ & $<1.0$ & 4.9 & $13 \%$ & 66 & 3290 & 89 & $<65.8$ & $<65.8$ & 340 & $12 \%$ & 40 & 2080 & 81 & $<40$ & $<40$ & $<40$ & $2 \%$ \\
\hline
\end{tabular}

LOQ: limit of quantitation. UL: upper limit of the calibration range. N: number of classrooms. F: frequency of classrooms with concentrations > LOQ

$\alpha$-HCH: $\alpha$-hexachlorocyclohexane, $\gamma$-HCH: $\gamma$-hexachlorocyclohexane (Lindane), 4,4'-DDT: dichlorodiphenyltrichloroethane, PAH: polycyclic aromatic hydrocarbon, PCB: polychlorobiphenyl, DMP: dimethyl-phthalate, DEP: diethyl phthalate, DiBP: diisobutyl-phthalate, DBP: dibutyl-phthalate, BBP: butyl benzyl phthalate, DEHP: bis(2-ethylhexyl)-phthalate, DiNP: diisononyl-phthalate, PBDE: polybromodiphenylether.

${ }^{a}$ Concentrations from less concentrated extracts for vacuumed dust

${ }^{b}$ Concentrations from less concentrated extracts for wiped dust

* unvalidated air sampling method, substance subject to degradation. 
Table 2. Paired data comparison of wiped dust vs. vacuumed dust

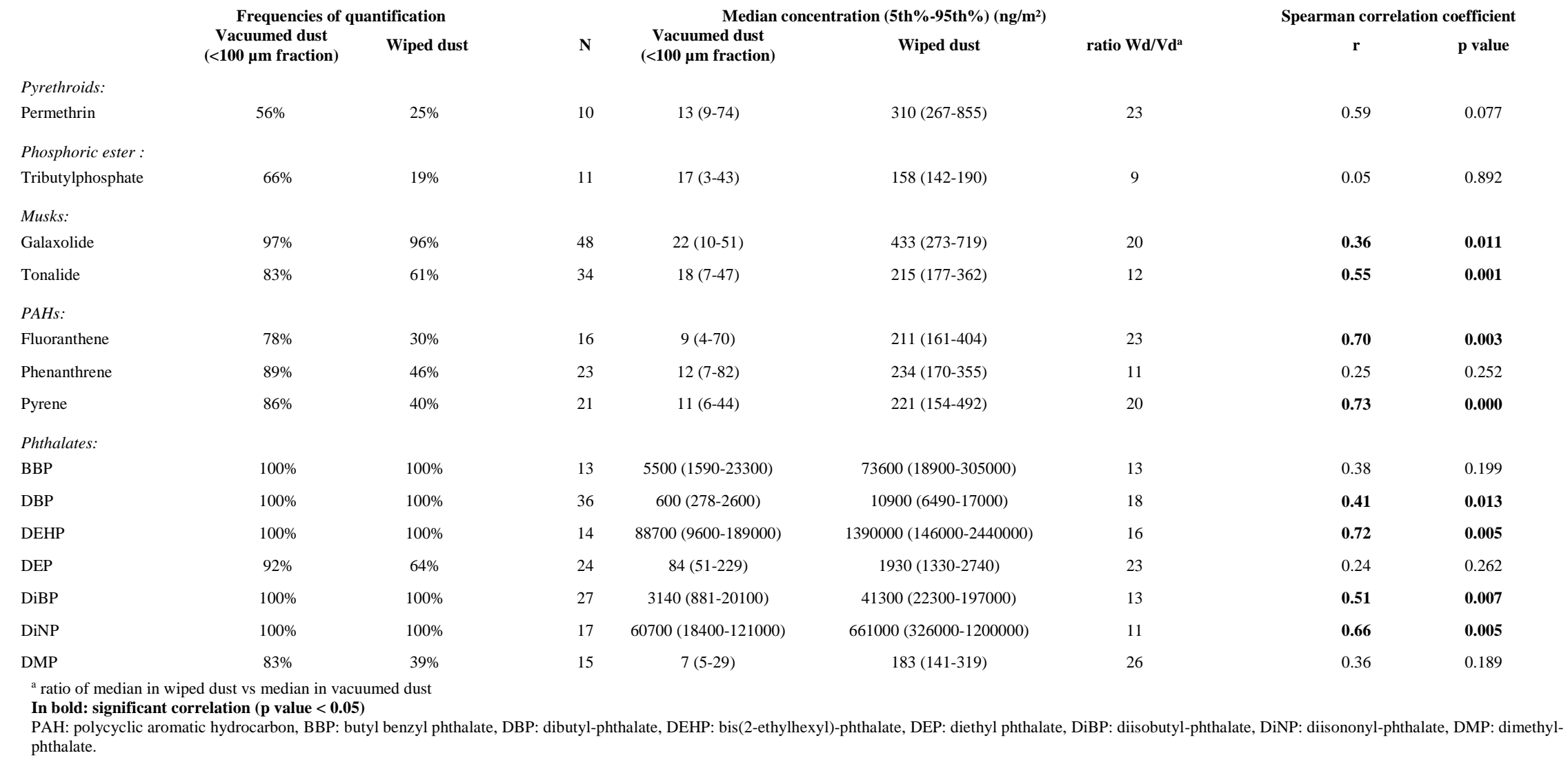




\section{Corresponding Author}

*EHESP - School of public health / LERES -Environment and health research laboratory

Avenue du Pr Léon Bernard

35043 Rennes Cedex France

Phone: + 33299022 922; fax: + 33299022 929; e-mail: gaelle.raffy@ehesp.fr.

\section{Funding sources}

This study was supported by the OQAI - French indoor air quality observatory, funded by the Ministries in charge of Housing, Environment and Health, the Environment and Energy Management Agency (ADEME), the Scientific and Technical Centre for Building and the French Agency for Food, Environmental and Occupational Health \& Safety (ANSES).

\section{Acknowledgment}

We are grateful to the administrators and head-teachers of the schools that participated in the study. The authors thank Delphine Pellé, Gaëlle Saramito, Erwann Gilles, Karine Elandaloussi, Isabelle Moratelli and Emilie Surget from the LERES - Environment and health research laboratory for their contributions to this work.

\section{References}

AFNOR (2007) XP X 4358, Ambiant air - Determination of crop protection substances (pesticides) in ambiant air - active sampling.

Ali, N., Dirtu, A.C., Eede, N. Van Den, Goosey, E., Harrad, S., Neels, H., ’t Mannetje, A., Coakley, J., Douwes, J. and Covaci, A. (2012) Occurrence of alternative flame retardants in indoor dust from New Zealand: indoor sources and human exposure assessment, Chemosphere, 88, 1276-1282.

Bennett, D.H., Moran, R.E., Wu, X., Tulve, N.S., Clifton, M.S., Colón, M., Weathers, W., Sjödin, A., Jones, R. and Hertz-Picciotto, I. (2014) Polybrominated diphenyl ether (PBDE) concentrations and resulting exposure in homes in California: relationships among passive air, surface wipe and dust concentrations, and temporal variability, Indoor Air, 25, 220-229.

Bi, X., Yuan, S., Pan, X., Winstead, C. and Wang, Q. (2015) Comparison, association, and risk assessment of phthalates in floor dust at different indoor environments in Delaware, USA, $J$. Environ. Sci. Heal. Part A, 50, 1428-1439. 
Blanchard, O. (2001) Mise au point des techniques de prélèvement et d'analyse des biocides dans l'environnement intérieur, Rapport INERIS - CSTB, October 2001.

Blanchard, O., Mercier, F., Ramalho, O., Mandin, C., Le Bot, B. and Glorennec, P. (2013) Measurements of semi-volatile organic compounds in settled dust: influence of storage temperature and duration, Indoor Air, 24, 125-135.

Blanchard, O., Glorennec, P., Mercier, F., Bonvallot, N., Chevrier, C., Ramalho, O., Mandin, C. and Lebot, B. (2014) Semi-volatile organic compounds in indoor air and settled dust in 30 French dwellings, Environ. Sci. Technol., 48, 3959-3969.

Bonvallot, N., Mandin, C., Mercier, F., Le Bot, B. and Glorennec, P. (2010) Health ranking of ingested semi-volatile organic compounds in house dust: an application to France, Indoor Air, 20, 458-472.

Bouvier, G., Blanchard, O., Momas, I. and Seta, N. (2006) Pesticide exposure of nonoccupationally exposed subjects compared to some occupational exposure: a French pilot study, Sci. Total Environ., 366, 74-91.

Bradman, A., Castorina, R., Gaspar, F., Nishioka, M., Colón, M., Weathers, W., Egeghy, P.P., Maddalena, R., Williams, J., Jenkins, P.L. and McKone, T.E. (2014) Flame retardant exposures in California early childhood education environments, Chemosphere, 116, 61-66.

Burrows, H.D., Canle L, M., Santaballa, J. a. and Steenken, S. (2002) Reaction pathways and mechanisms of photodegradation of pesticides, J. Photochem. Photobiol. B Biol., 67, 71108.

Canha, N., Mandin, C., Ramalho, O., Wyart, G., Ribéron, J., Dassonville, C., Hänninen, O., Almeida, S.M. and Derbez, M. (2015) Assessment of ventilation and indoor air pollutants in nursery and elementary schools in France, Indoor Air, DOI: 10.1111/ina.12222.

Cao, Z., Xu, F., Covaci, A., Wu, M., Yu, G., Wang, B., Deng, S. and Huang, J. (2014) Differences in the seasonal variation of brominated and phosphorus flame retardants in office dust, Environ. Int., 65, 100-106.

Cao, Z.-G., Yu, G., Chen, Y.-S., Cao, Q.-M., Fiedler, H., Deng, S.-B., Huang, J. and Wang, B. (2012) Particle size: a missing factor in risk assessment of human exposure to toxic chemicals in settled indoor dust, Environ. Int., 49, 24-30.

Cequier, E., Ionas, A.C., Covaci, A., Marcé, R.M., Becher, G. and Thomsen, C. (2014) Occurrence of a broad range of legacy and emerging flame retardants in indoor environments in Norway, Environ. Sci. Technol., 48, 6827-6835.

Cettier, J., Bayle, M.-L., Béranger, R., Billoir, E., Nuckols, J.R., Combourieu, B. and Fervers, B. (2015) Efficiency of wipe sampling on hard surfaces for pesticides and PCB residues in dust, Sci. Total Environ., 505, 11-21.

Clausen, P.A., Lindeberg Bille, R.L., Nilsson, T., Hansen, V., Svensmark, B. and Bøwadt, S. (2003) Simultaneous extraction of di(2-ethylhexyl) phthalate and nonionic surfactants from house dust. Concentrations in floor dust from 15 Danish schools, J. Chromatogr. A, 986, 179-190.

Clausen, P.A., Liu, Z., Kofoed-Sørensen, V., Little, J. and Wolkoff, P. (2012) Influence of 
temperature on the emission of di-(2-ethylhexyl)phthalate (DEHP) from PVC flooring in the emission cell FLEC, Environ. Sci. Technol., 46, 909-915.

Conrad, A., Seiwert, M., Hünken, A., Quarcoo, D., Schlaud, M. and Groneberg, D. (2013) The German environmental survey for children (GerES IV): reference values and distributions for time-location patterns of German children, Int. J. Hyg. Environ. Health, 216, 25-34.

Dalvie, M. a, Sosan, M.B., Africa, A., Cairncross, E. and London, L. (2014) Environmental monitoring of pesticide residues from farms at a neighbouring primary and pre-school in the Western Cape in South Africa, Sci. Total Environ., 466-467, 1078-1084.

ECHA (2009) Background document for benzyl butyl phthalate (BBP).

ECHA (2010) Background document for Diisobutyl phthalate (DIBP).

EPA (2011) Exposure Factors Handbook: 2011 Edition, Washington, DC.

Fournier, K., Glorennec, P. and Bonvallot, N. (2014) An exposure-based framework for grouping pollutants for a cumulative risk assessment approach: case study of indoor semi-volatile organic compounds, Environ. Res., 130, 20-28.

Fromme, H., Lahrz, T., Piloty, M., Gebhardt, H., Oddoy, A. and Rüden, H. (2004) Polycyclic aromatic hydrocarbons inside and outside of apartments in an urban area, Sci. Total Environ., 326, 143-9.

Fromme, H., Lahrz, T., Kraft, M., Fembacher, L., Dietrich, S., Sievering, S., Burghardt, R., Schuster, R., Bolte, G. and Völkel, W. (2013) Phthalates in German daycare centers: occurrence in air and dust and the excretion of their metabolites by children (LUPE 3), Environ. Int., 61, 64-72.

Fromme, H., Lahrz, T., Kraft, M., Fembacher, L., Mach, C., Dietrich, S., Burkardt, R., Völkel, W. and Göen, T. (2014) Organophosphate flame retardants and plasticizers in the air and dust in German daycare centers and human biomonitoring in visiting children (LUPE 3), Environ. Int., 71, 158-163.

Gaspar, F.W., Castorina, R., Maddalena, R.L., Nishioka, M.G., McKone, T.E. and Bradman, A. (2014) Phthalate exposure and risk assessment in california child care facilities, Environ. Sci. Technol., 48, 7593-7601.

González, O., Blanco, M.E., Iriarte, G., Bartolomé, L., Maguregui, M.I. and Alonso, R.M. (2014) Bioanalytical chromatographic method validation according to current regulations, with a special focus on the non-well defined parameters limit of quantification, robustness and matrix effect, J. Chromatogr. A, 1353, 10-27.

Harrad, S., Goosey, E., Desborough, J. and Abou-Elwafa Abdallah, M. (2010) Dust from U.K. primary school classrooms and daycare centers: the significance of dust as a pathway of exposure of young U.K. children to brominated flame retardants and polychlorinated biphenyls, Environ. Sci. Technol., 44, 4198-4202.

Hussein, T., Paasonen, P. and Kulmala, M. (2012) Activity pattern of a selected group of school occupants and their family members in Helsinki-Finland, Sci. Total Environ., 425, 289-92.

Hutter, H.-P., Haluza, D., Piegler, K., Hohenblum, P., Fröhlich, M., Scharf, S., Uhl, M., Damberger, B., Tappler, P., Kundi, M., Wallner, P. and Moshammer, H. (2013) Semivolatile 
compounds in schools and their influence on cognitive performance of children, Int. $J$. Occup. Med. Environ. Health, 26, 628-635.

Kanazawa, a, Saito, I., Araki, A., Takeda, M., Ma, M., Saijo, Y. and Kishi, R. (2010) Association between indoor exposure to semi-volatile organic compounds and buildingrelated symptoms among the occupants of residential dwellings, Indoor Air, 20, 72-84.

Kim, W., Choi, I., Jung, Y., Lee, J., Min, S. and Yoon, C. (2013) Phthalate levels in nursery schools and related factors, Environ. Sci. Technol., 47, 12459-12468.

Klepeis, N.E., Nelson, W.C., Ott, W.R., Robinson, J.P., Tsang, a M., Switzer, P., Behar, J. V, Hern, S.C. and Engelmann, W.H. (2001) The national human activity pattern survey (NHAPS): a resource for assessing exposure to environmental pollutants, J. Expo. Anal. Environ. Epidemiol., 11, 231-252.

Kohler, M., Tremp, J., Zennegg, M., Seiler, C., Minder-Kohler, S., Beck, M., Lienemann, P., Wegmann, L. and Schmid, P. (2005) Joint sealants: An overlooked diffuse source of polychlorinated biphenyls in buildings, Environ. Sci. Technol., 39, 1967-1973.

Langer, S., Weschler, C.J., Fischer, A., Bekö, G., Toftum, J. and Clausen, G. (2010) Phthalate and PAH concentrations in dust collected from Danish homes and daycare centers, Atmos. Environ., 44, 2294-2301.

Le Bot, B., Gilles, E., Durand, S. and Glorennec, P. (2010) Bioaccessible and quasi-total metals in soil and indoor dust, Eur. J. Mineral., 22, 651-657.

Le Cann, P., Bonvallot, N., Glorennec, P., Deguen, S., Goeury, C. and Le Bot, B. (2011) Indoor environment and children's health: recent developments in chemical, biological, physical and social aspects, Int. J. Hyg. Environ. Health, 215, 1-18.

Lim, Y.-W., Kim, H.-H., Lee, C.-S., Shin, D.-C., Chang, Y.-S. and Yang, J.-Y. (2014) Exposure assessment and health risk of poly-brominated diphenyl ether (PBDE) flame retardants in the indoor environment of elementary school students in Korea, Sci. Total Environ., 470471, 1376-1389.

Lioy, P.J., Freeman, N.C.G. and Millette, J.R. (2002) Dust: A metric for use in residential and building exposure assessment and source characterization, Environ. Health Perspect., 110, 969-983.

Mandin, C., Mercier, F., Lucas, J.-P., Ramalho, O., Blanchard, O., Bonvallot, N., Raffy, G., Gilles, E., Glorennec, P. and Le Bot, B. (2013) Semi-volatile organic compounds in home settled dust: a nationwide survey in France. In: Conference on Environment and Health, 1923 August 2013, Basel, Switzerland.

Meeker, J.D. and Stapleton, H.M. (2010) House dust concentrations of organophosphate flame retardants in relation to hormone levels and semen quality parameters, Environ. Health Perspect., 118, 318-323.

Meeker, J.D., Cooper, E.M., Stapleton, H.M. and Hauser, R. (2013) Urinary metabolites of organophosphate flame retardants: Temporal variability and correlations with house dust concentrations, Environ. Health Perspect., 121, 580-585.

Mercier, F., Glorennec, P., Thomas, O. and Le Bot, B. (2011) Organic contamination of settled 
house dust, a review for exposure assessment purposes, Environ. Sci. Technol., 45, 67166727.

Mercier, F., Gilles, E., Saramito, G., Glorennec, P. and Le Bot, B. (2014) A multi-residue method for the simultaneous analysis in indoor dust of several classes of semi-volatile organic compounds by pressurized liquid extraction and gas chromatography/tandem mass spectrometry, J. Chromatogr. A, 1336, 101-111.

Mizouchi, S., Ichiba, M., Takigami, H., Kajiwara, N., Takamuku, T., Miyajima, T., Kodama, H., Someya, T. and Ueno, D. (2015) Exposure assessment of organophosphorus and organobromine flame retardants via indoor dust from elementary schools and domestic houses, Chemosphere, 123, 17-25.

Morgan, M.K., Sheldon, L.S., Croghan, C.W., Jones, P. a, Chuang, J.C. and Wilson, N.K. (2007) An observational study of 127 preschool children at their homes and daycare centers in Ohio: environmental pathways to cis- and trans-permethrin exposure, Environ. Res., 104, 266-274.

Oomen, A.G. (2008) Exposure to chemicals via house dust.

Rivas, I., Viana, M., Moreno, T., Pandolfi, M., Amato, F., Reche, C., Bouso, L., ÀlvarezPedrerol, M., Alastuey, a., Sunyer, J. and Querol, X. (2014) Child exposure to indoor and outdoor air pollutants in schools in Barcelona, Spain, Environ. Int., 69, 200-212.

Roosens, L., Covaci, A. and Neels, H. (2007) Concentrations of synthetic musk compounds in personal care and sanitation products and human exposure profiles through dermal application, Chemosphere, 69, 1540-1547.

Rudel, R. a and Perovich, L.J. (2009) Endocrine disrupting chemicals in indoor and outdoor air, Atmos. Environ. (1994)., 43, 170-181.

Sofuoglu, a, Kiymet, N., Kavcar, P. and Sofuoglu, S.C. (2010) Polycyclic and nitro musks in indoor air: a primary school classroom and a women's sport center, Indoor Air, 20, 515-22.

Toms, L.-M.L., Mazaheri, M., Brommer, S., Clifford, S., Drage, D., Mueller, J.F., Thai, P., Harrad, S., Morawska, L. and Harden, F. a. (2015) Polybrominated diphenyl ethers (PBDEs) in dust from primary schools in South East Queensland, Australia, Environ. Res., 142, 135140.

US EPA (2010) Reregistration Eligibility Decision (RED) Document for Tetramethrin.

Wallner, P., Kundi, M., Moshammer, H., Piegler, K., Hohenblum, P., Scharf, S., Fröhlich, M., Damberger, B., Tappler, P. and Hutter, H.-P. (2012) Indoor air in schools and lung function of Austrian school children, J. Environ. Monit., 14, 1976-1982.

Wason, S.C., Julien, R., Perry, M.J., Smith, T.J. and Levy, J.I. (2013) Modeling exposures to organophosphates and pyrethroids for children living in an urban low-income environment, Environ. Res., 124, 13-22.

Watkins, D.J., McClean, M.D., Fraser, A.J., Weinberg, J., Stapleton, H.M. and Webster, T.F. (2013) Associations between PBDEs in office air, dust, and surface wipes, Environ. Int., 59, 124-32.

Wei, W., Boumier, J., Wyart, G., Ramalho, O. and Mandin, C. (2015) Cleaning practices and 
cleaning products in nurseries and schools: to what extent can they impact indoor air quality?, Indoor Air, DOI: 10.1111/ina.12236.

Weschler, C.J. (2009) Changes in indoor pollutants since the 1950s, Atmos. Environ., 43, 153169.

Weschler, C.J. and Nazaroff, W.W. (2008) Semivolatile organic compounds in indoor environments, Atmos. Environ., 42, 9018-9040.

Weschler, C.J. and Nazaroff, W.W. (2010) SVOC partitioning between the gas phase and settled dust indoors, Atmos. Environ., 44, 3609-3620.

WHO (1989) Indoor air quality: Organic pollutants (EURO Reports and Studies No. 111.).

Wilson, N.K., Chuang, J.C., Lyu, C., Menton, R. and Morgan, M.K. (2003) Aggregate exposures of nine preschool children to persistent organic pollutants at day care and at home, J. Expo. Anal. Environ. Epidemiol., 13, 187-202.

Wu, Q., Baek, S.-Y., Fang, M. and Chang, Y.-S. (2010) Distribution and fate of polybrominated diphenyl ethers in indoor environments of elementary schools, Indoor Air, 20, 263-270.

Wu, Y., Cox, S.S., Xu, Y., Liang, Y., Won, D., Liu, X., Clausen, P. a., Rosell, L., Benning, J.L., Zhang, Y. and Little, J.C. (2016) A reference method for measuring emissions of SVOCs in small chambers, Build. Environ., 95, 126-132.

Zhang, L.H., Li, P.J., Gong, Z.Q. and Oni Adeola, a. (2006) Photochemical behavior of benzo[a]pyrene on soil surfaces under UV light irradiation, J. Environ. Sci. (China), 18, 1226-1232.

Zmirou, D., Gauvin, S., Pin, I., Momas, I., Just, J., Sahraoui, F., Le Moullec, Y., Brémont, F., Cassadou, S., Albertini, M., Lauvergne, N., Chiron, M. and Labbé, A. (2002) Five epidemiological studies on transport and asthma: objectives, design and descriptive results, J. Expo. Anal. Environ. Epidemiol., 12, 186-196. 